\title{
EVALUATION OF FUNCTIONAL CONDITION OF RESPIRATORY MUSCLES OF PATIENTS WITH A COMPLICATED BRONCHIAL ASTHMA PATHOLOGY AND CHRONIC OBSTRUCTIVE PULMONARY DISEASES Yuriy Feschenko \\ Department of pulmonology \\ SI«National institute of phthysiology and pulmonology \\ named after F. G. Ianovskyi NAMS of Ukraine» \\ 10 Amosova str., Kyiv, Ukraine, 03680 \\ admin@ifp.kiev.ua \\ Ksenia Nazarenko \\ Department of pulmonology \\ SI «National institute of phthysiology and pulmonology \\ named after F.G. Ianovskyi NAMS of Ukraine» \\ 10 Amosova str., Kyiv, Ukraine, 03680 \\ k.nazarenko123@gmail.com
}

\begin{abstract}
The aim of the research was to study the functional state of respiratory muscles and neuro-respiratory drive in patients with a combined pathology of bronchial asthma and chronic obstructive pulmonary disease.

The functional condition of the respiratory muscles and the tone of the respiratory centre were determined with the help of a device for occlusion spirometry. Also, the patient was observed with a spirometry, a general plethysmography of the body.

Materials and methods. 140 patients with combined broncho-obstructive pathology, 34 patients with asthma and 17 patients with COPD were examined. Spirometry, general plethysmography of the body and occlusion spirometry were provided for all patients.

Results show a decrease in muscle strength of breath in all categories of patients with broncho-obstructive diseases, especially expressed in patients with bronchial asthma and asthma-COPD intersection. The muscle strength of breath was maintained with a significant increase in COPD patients compared with those with bronchial asthma. With increasing broncho-obstruction in patients with asthma-COPD intersection, there was a progressive and reliable decrease in muscle strength for breath and expiration, as well as a tendency to increase neuron respiratory drive. In patients with asthma-COPD intersection with more expressed symptoms revealed a significant and reliable weakening of muscle strength for breath and increased neuro-respiratory drive. During the work were obtained reliable links of the parameters of respiratory muscle strength not only with the parameters of pulmonary volume and bronchial patency, but also with the degree of neutrophilic inflammation in this category of patients.

Conclusions. The obtained data on failure of the functional state of the respiratory muscles and the neuro-respiratory drive can be used in the development of rehabilitation programs for the management of patients with combined broncho-obstructive pathology.

Keywords: combination of bronchial asthma and chronic obstructive pulmonary disease, respiratory muscle strength, neuro-respiratory drive.
\end{abstract}

\section{Introduction}

In a number of issues of modern medical science and practice, a significant place is occupied by broncho-obstructive diseases: bronchial asthma (BA) and chronic obstructive pulmonary disease (COPD). Recently, a combination of these two diseases, the so-called asthma-COPD intersection (ACP), characterized by more expressed symptoms, frequent exacerbations and worse prognosis in comparison with two pathologies separately [1, 2].

Despite the ongoing research and analysis of data on this pathological condition, the state of respiratory muscles in this category of patients remains uncertain. In connection with the importance of the pathogenetic influence of respiratory muscles on the development of symptoms, manifestations of broncho-obstructive diseases, as well as its role in the formation of chronic pulmonary insufficiency, it becomes obvious the need to take into account its condition and properties for the management of such patients. 
One of the most commonly used methods for assessing the functional state of respiratory muscles in Ukraine and in the world is occlusive spirometry, which allows non-invasive and with minimal effort of patients to define discoordination in the work of respiratory muscles and changes in the central regulation of the respiration process $[3,4]$.

\section{Aim of the research}

Determination of features of the functional state of respiratory muscles and neuro-respiratory drive in patients with combined pathology of asthma and COPD, depending on the severity and nature of the disease.

\section{Materials and methods}

Patients with symptoms of BA+COPD were included in the study. The diagnosis was exposed according to the criteria given in GINA and GOLD [5, 6]. All patients had persistent, but variable symptoms that are specific for asthma and COPD, the state of patients was stable, no exacerbation in 2 months period before the study began. During the evaluating of the function of external respiration (FER) in all patients were determined signs of bronchial rejection - an increase in volume of forced exhalation for $1 \mathrm{~s}$ (VFE1) in $200 \mathrm{ml}$ and $12 \%$ or more after application of bronchodilator (400 mcg of salbutamol), indications of the presence of fixed broncho-obstruction - ratio of forced exhalation for the first second/forced lung capacity (VFE1/FLC) $<70 \%$ after bronchodilator. Also, the study included patients with asthma and COPD. Characteristics of patients are given in Table 1.

Table 1

Characteristics of patients and healthy persons

\begin{tabular}{|c|c|c|c|}
\hline Indicators & BA $(n=34)$ & COPD $(n=17)$ & BA+ COPD $(n=140)$ \\
\hline $\operatorname{Sex}(n)$ & $\begin{array}{l}27 \text { women } \\
7 \text { men }\end{array}$ & $\begin{array}{l}7 \text { women } \\
10 \text { men }\end{array}$ & $\begin{array}{l}74 \text { women } \\
66 \text { men }\end{array}$ \\
\hline Age, years & $50.76 \pm 1.5$ & $67.36 \pm 2.27$ & $58.56 \pm 0.81$ \\
\hline Body mass index, $\mathrm{kg} / \mathrm{m}^{2}$ & $31.64 \pm 1.39$ & $30.02 \pm 1.46$ & $28.82 \pm 0.43$ \\
\hline \multicolumn{4}{|c|}{ Degree of severity of asthma } \\
\hline easy, $(\%)$ & 32 & & 6 \\
\hline medium severity (\%) & 59 & & 79 \\
\hline hard $(\%)$ & 9 & & 15 \\
\hline \multicolumn{4}{|c|}{ Groups of patients with COPD } \\
\hline $\mathrm{A}(\%)$ & & 18 & 13 \\
\hline $\mathrm{B}(\%)$ & & 11 & 21 \\
\hline $\mathrm{C}(\%)$ & & 18 & 20 \\
\hline $\mathrm{D}(\%)$ & & 53 & 46 \\
\hline \multicolumn{4}{|c|}{ GOLD grade for VFE1 } \\
\hline $1(\%)$ & & 29 & 29 \\
\hline $2(\%)$ & & 29 & 58 \\
\hline $3(\%)$ & & 36 & 11 \\
\hline $4(\%)$ & & 6 & 2 \\
\hline $\begin{array}{l}\text { Number of exacerbations for } \\
\text { the previous year (n) }\end{array}$ & $2.42 \pm 0.23$ & $1.82 \pm 0.18$ & $2.55 \pm 0.15$ \\
\hline $\begin{array}{l}\text { Number of hospitalizations for } \\
\text { the previous year (n) }\end{array}$ & $0.76 \pm 0.17$ & $0.94 \pm 0.16$ & $1.06 \pm 0.09$ \\
\hline $\begin{array}{l}\text { Number of courses of systemic } \\
\text { corticosteroids for the previous year (n) }\end{array}$ & $1.15 \pm 0.19$ & $1.12 \pm 0.2$ & $1.32 \pm 0.1$ \\
\hline $\begin{array}{l}\text { Number of courses of antibiotic therapy } \\
\text { for the previous year (n) }\end{array}$ & $0.53 \pm 0.13$ & $1.0 \pm 0.15$ & $0.94 \pm 0.06$ \\
\hline
\end{tabular}


The functional state of the respiratory muscles and the tone of the respiratory centre were determined with the help of a device for occlusion spirometry. The main indicators for assessing the state of inhalation and exhalation muscles, as well as for the respiratory centre were PImax (inspirational muscle strength), PEmax (exuding muscle strength), and P0.1 (neuro-respiratory drive).

Also, the patient was observed with a spirometry, a general plethysmography of the body (JaegerMasterScreen, ErichJaegerGmbH, Germany) with the methods of the company-developer. The study was conducted in the morning, after a 12-14 hour break in the administration of drugs. All patients also determined the level of interleukin 17 blood serum on an empty stomach by the method of immunoassay analysis on the device Biotec ELx808 (USA).

Data accumulation and their mathematical processing were carried out with the help of licensed software products included in the package Microsoft Office Professional 2007, the license Russian Academic OPEN NoLevel number 43437596. Statistical processing was performed using mathematical and statistical capabilities of MS Excel. The parameters investigated in the study were evaluated by means of determining the average $(\mathrm{M})$, the mean error $(\mathrm{m})$, the reliability $(\mathrm{t})$, the significance level (p), followed by comparison using the t-criterion of the Student and the U-The Mann-Whitney Criterion, depending on the type of distribution of the received data. The verification of the numeric rows for compliance with normal distribution was carried out using the special function NORMSAMP_1 developed for the Excel program.

\section{Results of the research}

The analysis of the results of occlusion spirometry made it possible to conclude that in all categories of patients with broncho-obstructive diseases there is a decrease in the strength of inspiratory muscle, which are most expressed in patients with asthma and ACP. The power of expiratory muscles of patients with COPD was significantly higher in compare to those with asthma. The force of expiratory muscles of patients with ACP was significantly lower than those with COPD. Also, in patients with acute respiratory virulence, there was a significant increase in neuro-respiratory drive in compare to those with asthma and COPD. The data is shown in the Table 2.

Table 2

Indicators of respiratory muscle strength in patients with $\mathrm{BA}, \mathrm{COPD}$ and $\mathrm{ACP}$

\begin{tabular}{ccccc}
\hline Indicators & BA & COPD & ACP & $54.6 \pm 2.2$ \\
PImax, \% & $51.2 \pm 4.3$ & $58.1 \pm 6.3$ & $74.9 \pm 2.9 \alpha$ \\
PEmax, \% & $71.6 \pm 7.5$ & $83.3 \pm 5.6^{*}$ & \\
P0.1, \% & $122.3 \pm 8.1$ & $136.6 \pm 15.7$ & $162.4 \pm 10.0 * * \alpha$
\end{tabular}

Note: ${ }^{*}-p<0.05 ; * *-p<0.01$ in compare to $B A ; \alpha-p<0.05 ; \alpha-p<0.01$ in compare to COPD

In patients with low broncho-obstruction (GOLD 1 group), the rate of inspiration muscle strength was within the normal range, but with increased broncho-obstruction, there was a significant decrease in the above-mentioned indicator (in patients from the GOLD 2 group, a significant decrease in PImax in compare to the GOLD 1 group). Also, with increased broncho-obstruction, there was a significant decrease in the strength of the exhalation muscles, which was most expressed in patients with VFE1 $<50 \%$ (GOLD 3-4 group). The data is shown in the Table 3.

During the compare of the indicators of occlusion spirometry of patients with ACP, depending on the state of symptoms and the number of exacerbations (when distributed according to the clinical groups of GOLD), a reliable and significant decrease in inspiration muscle strength, a tendency to decrease exhalation muscle strength and a significant increase in neuro-respiratory drive in patients with ACP with more expressed symptoms (GOLD B, D group). The data is shown in the Table 4. 
Table 3

Indicators of the respiratory muscles strength of patients with ACP, depending on the degree of bronchoobstruction

\begin{tabular}{cccc}
\hline Indexes & GOLD 1 & GOLD 2 & GOLD 3-4 \\
\hline PImax, \% & $62.5 \pm 4.4$ & $51.4 \pm 2.7^{*}$ & $50.7 \pm 6.5$ \\
PEmax, \% & $82.1 \pm 4.9$ & $74.4 \pm 4.2$ & $60.7 \pm 5.5^{* *} \alpha$ \\
P0.1, \% & $153.2 \pm 25.1$ & $160.2 \pm 10.8$ & $193.4 \pm 17.4$
\end{tabular}

Note: ${ }^{*}-p<0.05 ;{ }^{*}{ }_{-} p<0.01$ in compare to GOLD 1; $\alpha-p<0.05$

Table 4

Indicators of respiratory muscle strength of ACP patients $\mathrm{w}$ depending on the clinical group of patients classified by GOLD

\begin{tabular}{ccc}
\hline Indexes & GOLD A,C & GOLD B,D \\
\hline PImax, \% & $63.8 \pm 4.4$ & $50.1 \pm 2.4^{* *}$ \\
PEmax, \% & $73.7 \pm 3.6$ & $75.4 \pm 4.0$ \\
P0.1, \% & $127.6 \pm 13.1$ & $179.5 \pm 12.9^{* *}$
\end{tabular}

Note: ${ }^{* *}-p<0.01$ in compare to GOLD A,C

One of the main symptoms of broncho-obstructive illness is dyspnea, which progresses (over time, worsens), persists (available daily), worsens during exercise and respiratory infections [7-9]. There are several validated questionnaires for assessing the symptoms in COPD patients. GOLD suggests applying the Modified Scale to assess the severity of shortness of breath. The modified dyspnea scale correlates well with other instruments for measuring the health status [10-12]. The scale includes 5 statements, which contain the entire spectrum of pulmonary insufficiency from 0 (no dyspnea) to 4 (maximum expressed dyspnea).

One of the objectives of the study was to assess the state of the respiratory muscles, depending on the severity of dyspnea, which was assessed using the MDR scale. With increasing dyspnea in patients with ACP, there was a reliable and significant decrease in inspiration muscle strength and increased neuro-respiratory drive. The data is shown in the Table $\mathbf{5}$.

Table 5

Indicators of the strength of respiratory muscles of patients with ACP, depending on the level of shortness of breath

\begin{tabular}{ccc}
\hline Indexes & MDR 0-1 & MDR 2 \\
\hline PImax, \% & $63.1 \pm 4.4$ & $50.3 \pm 2.4^{* *}$ \\
PEmax, \% & $73.6 \pm 3.5$ & $75.5 \pm 4.1$ \\
P0.1, \% & $127.1 \pm 12.8$ & $180.3 \pm 13.0^{* *}$
\end{tabular}

Note: $* *-p<0.01$ in compare to $m M R C 0-1$

A comparative analysis of occlusion spirometry indices in patients with different age groups was also conducted. At the same time, a significant decrease in inspiration muscle strength and increased neuro-respiratory drive in patients with ACP over the age of 70 years in compare to patients of younger age groups. The data is shown in the Table 6.

At the last stage of the work, a correlation analysis of functional parameters of respiratory muscle and pulmonary volume, bronchial patency and anti-inflammatory cytokine levels in patients with ACP was performed. 
Table 6

Indicators of the strength of respiratory muscles of ACP patients, depending on age

\begin{tabular}{cccc}
\hline Indexes & Age $<\mathbf{5 0}$ years & Age 50-70 years & Age $>$ 70 years \\
\hline PImax, \% & $66.7 \pm 8.3$ & $54.5 \pm 2.3$ & $41.3 \pm 3.5^{* *} \alpha \alpha$ \\
PEmax, \% & $71.8 \pm 7.0$ & $77.0 \pm 3.7$ & $67.2 \pm 6.0$ \\
P0.1, \% & $153.6 \pm 27.3$ & $167.3 \pm 12.3$ & $147.3 \pm 14.7$
\end{tabular}

Note: $* *-p<0.01$ in compare to age $<50$ years; $\alpha \alpha p<0.01$ in compare to age $50-70$ years

Patients with ACP had a significant positive correlation link of the medium strength between the volume of forced exhalation in 1 second and inspiration muscle strength $(\mathrm{r}=0.51$, p $<0.05)$ (Fig. 1).

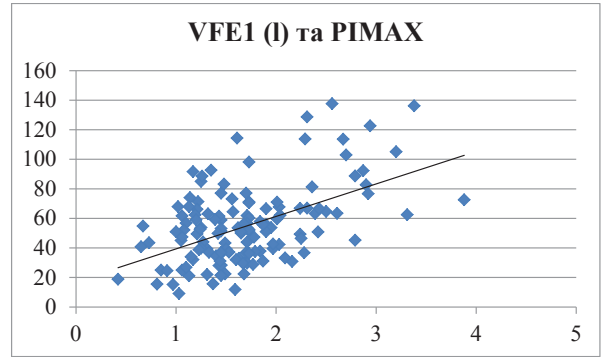

Fig. 1. Correlation link between the force of muscles and the VFE1

Also, in ACP patients there was a significant positive correlation link of the low strength between the general resistance of the lungs and the degree of neuro-respiratory drive $(r=0.54$, $\mathrm{p}<0.05$ ) (Fig. 2).

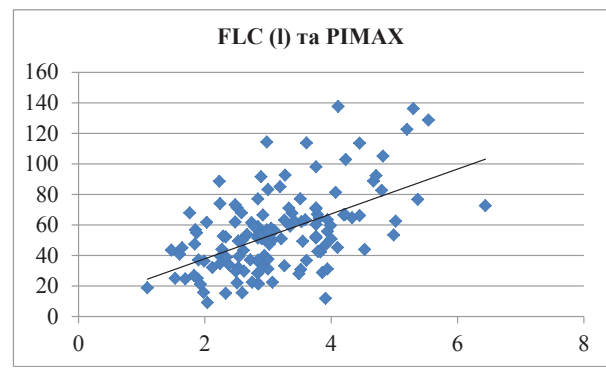

Fig. 2. Correlation link between the strength of the muscles of inspiration and FLC

Patients with ACP had a significant positive correlation link of low strength between bronchial resistance and the degree of neuro-respiratory drive $(r=0.36, p<0.05)($ Fig. 3$)$.

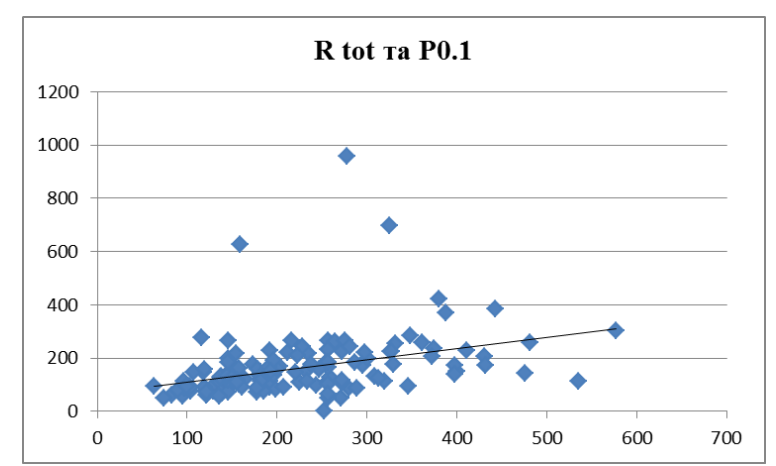

Fig. 3. Correlation link between the index of neuron-respiratory drive and general bronchial resistance 
Patients with ACP had a significant positive correlation link of low strength between interleukin 17 and the degree of neuro-respiratory drive $(r=0.25, \mathrm{p}<0.05)$ (Fig. 4).

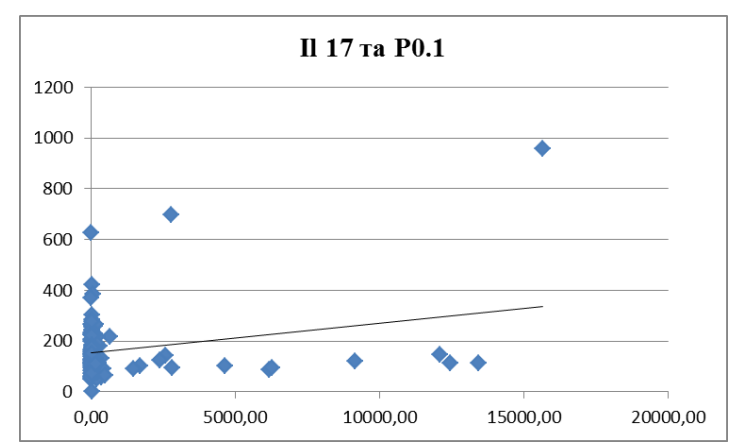

Fig. 4. Correlation link between the index of neuron-respiratory drive and level of I117

\section{Discussion}

The results of our study show a decrease in muscle strength in the inspiration muscles in all categories of patients with broncho-obstructive diseases, especially expressed in patients with asthma and ACP. The muscle strength of the exhalation was maintained with a significant increase in COPD patients in compare to those with asthma.

Respiratory muscles in broncho-obstructive diseases operate in conditions of increased load, increased resistance, caused by the presence of hyperinflation and reduction of bronchial compliance [13-15]. Resistance of respiratory tract in patients with COPD is 5-15 times higher in comparison with such of healthy persons. Hyperinflation also contributes to reducing the contractile properties of respiratory muscles [16-18].

With the strengthening of broncho-obstruction in patients with ACP, there was a progressive and reliable decrease in exhalation and inspiration muscle strength, as well as the tendency to increase neuro-respiratory drive.

$\mathrm{P} 0.1$ reflects the reduction of respiratory pressure in the first $100 \mathrm{~ms}$ of an independent attempt to breathe a patient with occlusion of the respiratory tract. For patients with obstructive or restrictive pathology, this indicator usually increases, as breathing is accompanied by additional efforts to overcome the increased resistance of the respiratory tract. Thus, an increase in neuro-respiratory drive is a criterion for increased work of breathing of patients [19].

Patients with ACP with more expressed symptoms revealed a significant and reliable weakening of inspiration muscle strength and increased neuro-respiratory drive. In particular, such a symptom as dyspnea significantly and reliably influenced on the above parameters of patients with ACP.

Over time, the muscle strength was reliably reduced in dysfunction without significant changes in other parameters of the functional state of the respiratory muscles.

Reliable positive correlations of the parameters of bronchial patency and pulmonary volume with inspiration muscle strength confirm the negative effect of broncho-obstruction on the strength of respiratory muscles in patients with combined broncho-obstruction pathology [20].

The degree of central regulation of respiration (neuro-respiratory drive) is also independently associated with the overall bronchial resistance (Rtot) and the level of anti-inflammatory cytokine II 17, which is known to support the activity of neutrophilic inflammation in broncho-obstructive diseases.

Thus, during the work were obtained reliable links of the parameters of the respiratory muscle strength not only with the parameters of pulmonary volume and bronchial patency, but also with the degree of neutrophilic inflammation in this category of patients.

\section{Conclusions}

1. Patients with asthma, COPD and their combination had dysfunctions of respiratory muscles of varying severity.

2. The highest degree of dysfunctions in the work of respiratory muscles was found in patients with acute respiratory virulence with a high level of bronchial obstruction, with severe symptoms, in particular shortness of breath, and older. 
3. During the course of work was revealed a reliable link between the severity of functional disorders of the respiratory muscles, pulmonary volume and patency of the bronchi, as well as the severity of neutrophilic inflammation.

4. The obtained data can be used in the development of rehabilitation programs for the management of patients with combined broncho-obstructive pathology.

\section{References}

[1] Hines, K. L., Peebles, R. S. (2017). Management of the Asthma-COPD Overlap Syndrome (ACOS): a Review of the Evidence, 15-19. Current Allergy and Asthma Reports, 17 (3). doi: 10.1007/s11882-017-0683-4

[2] Bujarski, S., Parulekar, A. D., Sharafkhaneh, A., Hanania, N. A. (2015). The Asthma COPD Overlap Syndrome (ACOS). Current Allergy and Asthma Reports, 15 (3), 509. doi: 10.1007/s11882-014-0509-6

[3] De Troyer, A., Boriek, A. M. (2011). Mechanics of the Respiratory Muscles. Comprehensive Physiology, 1, 1273-1300. doi: 10.1002/cphy.c100009

[4] Evangelista, M. de A., Dias, F. A. L., Dourado Junior, M. E. T., do Nascimento, G. C., Sarmento, A., Gualdi, L. P. et. al. (2017). Noninvasive assessment of respiratory muscle strength and activity in Myotonic dystrophy. PLOS ONE, 12 (6), e0177318. doi: 10.1371/journal.pone.0177318

[5] Global Strategy for Asthma Management and Prevention (2017). The Global Initiative for asthma (GINA). Available at: http://ginasthma.org/2017-gina-report-global-strategy-for-asthma-management-and-prevention/

[6] GOLD 2017. Global Strategy for the Diagnosis, Management and Prevention of COPD (2017). Global Initiative for Chronic Obstructive Lung Disease. Available at: http://goldcopd.org/gold-2017-globalstrategy-diagnosis-management-prevention-copd/

[7] Marciniuk, D. D., Goodridge, D., Hernandez, P., Rocker, G., Balter, M. et. al. (2011). Managing Dyspnea in Patients with Advanced Chronic Obstructive Pulmonary Disease: A Canadian Thoracic Society Clinical Practice Guideline. Canadian Respiratory Journal, 18 (2), 69-78. doi: 10.1155/2011/745047

[8] Anzueto, A., Miravitlles, M. (2017). Pathophysiology of dyspnea in COPD. Postgraduate Medicine, 129 (3), 366-374. doi: 10.1080/00325481.2017.1301190

[9] Mostovyi, Yu. (2016). Khronichne obstruktyvne zakhvoriuvannia lehen. Kliuchovi pytannia. Ukrainskyi medychnyi chasopys, 4, 63-65.

[10] Uniflkovaniy klnichniy protokol pervinnoyi (vtorinnoyi) spetsializovanoyi, tretinnoyi (visokospetsializovanoyi) medichnoyi dopomogi tamedichnoy ireabilitatsii "Hronichne obstruktivne zahvoryuvannya legen" (2013). MOZ Ukrayini, No. 555. Pro zatverdzhennya standartizatsii medichnoi dopomogi pri HOZL. Available at: http://meduha.net/content/unifikovaniy-klinichniy-protokol-pervinnoyi-vtorinnoyi-specializovanoyi-tretinnoyi

[11] Gavrisyuk, V. K. (2016). Respiratornaya nedostatochnost: mehanizmy razvitiya, sposoby otsenki, oksigenoterapiya. Ukrayinskiy pulmonologichniy zhurnal, 4, 56-58.

[12] Jones, P. W., Adamek, L., Nadeau, G., Banik, N. (2013). Comparisons of health status scores with MRC grades in COPD: implications for the GOLD 2011 classification. European Respiratory Journal, 42 (3), 647-654. doi: 10.1183/09031936.00125612

[13] Segizbaeva, M. O., Timofeev, N. N., Donina, Z. A., Kur’yanovich, E. N., Aleksandrova, N. P. (2014). Effects of Inspiratory Muscle Training on Resistance to Fatigue of Respiratory Muscles During Exhaustive Exercise. Advances in Experimental Medicine and Biology, 840, 35-43. doi: 10.1007/5584_2014_20

[14] Aliverti, A. (2016). The respiratory muscles during exercise. Breathe, 12 (2), 165-168. doi: $10.1183 / 20734735.008116$

[15] Klimathianaki, M., Vaporidi, K., Georgopoulos, D. (2011). Respiratory Muscle Dysfunction in COPD: From Muscle to Cell. Current Drug Targets, 12 (4), 478-488. doi: 10.2174/138945011794751474

[16] Gagnon, P., Guenette, J., Langer, D., Laviolette, L., Mainguy, V. et. al. (2014). Pathogenesis of hyperinflation in chronic obstructive pulmonary disease. International Journal of Chronic Obstructive Pulmonary Disease, 9 (1), 187-201. doi: 10.2147/copd.s38934

[17] Wu, A. (2006). Respiratory muscle activity and respiratory obstruction after abdominal surgery. British Journal of Anaesthesia, 96 (4), 510-515. doi: 10.1093/bja/ael035

[18] Hogg, J. C., McDonough, J. E., Suzuki, M. (2013). Small Airway Obstruction in COPD. Chest, 143 (5), 1436-1443. doi: 10.1378/chest.12-1766 
[19] Vargas, F., Boyer, A., Bui, H. N., Salmi, L. R., Guenard, H., Gruson, D., Hilbert, G. (2008). Respiratory failure in chronic obstructive pulmonary disease after extubation: value of expiratory flow limitation and airway occlusion pressure after 0.1 second (P0.1). Journal of Critical Care, 23 (4), 577-584. doi: $10.1016 /$ j.jcrc.2007.12.009

[20] Kim, N.-S., Seo, J.-H., Ko, M.-H., Park, S.-H., Kang, S.-W., Won, Y. H. (2017). Respiratory Muscle Strength in Patients With Chronic Obstructive Pulmonary Disease. Annals of Rehabilitation Medicine, 41 (4), 659-666. doi: 10.5535/arm.2017.41.4.659

\title{
ELIMINATION OF CONGENITAL SYPHILIS IN UKRAINE: ANALYSIS AND THE EMERGING ISSUES
}

\author{
Lyudmyla Derevyanko \\ Department of preventive activities and coordination of co-operation with WHO \\ Ukrainian Institution of Strategic Studies of the Ministry of Health \\ 3 Volgo-Donsky ave., Kyiv, Ukraine, 02000 \\ l.derevyanko@kmu.edu.ua
}

\begin{abstract}
The objective of this study is to analyze the indicators of the process of elimination of mother-to-child transmission of syphilis in Ukraine thus helping to prepare for elimination of this process according to the WHO targets and criteria.

Epidemiological and clinical data of 237 women who had syphilis before or during pregnancy and babies born to them (238) from 1999 to 2007 years were presented. In addition were used statistical forms of the Public Health Center and Center for Medical Statistics of the Ministry of Health of Ukraine for the incidence of syphilis and HIV in women of reproductive age, pregnant women and children born to them, including those who were diagnosed with congenital syphilis (CS) and HIV infection.

Analysis of the causes of CS suggests that the main risk factors in Ukraine were the lack of prenatal care in $44 \%$ and treatment in $99 \%$ of pregnant women with syphilis. Besides out-of-date normative base regulating STI diagnostic and care create delay in diagnostics and treatment of pregnant women and their newborns.

In addition, the delay with prenatal diagnosis and treatment, late infection, quality of diagnostics, iatrogenic errors, refusal of women from current requirement for hospitalization, reinfection, and birth at home can be attributed to risk factors for CS.

Despite the main target indicator of CS elimination has been achieved, process indicators of syphilis as coverage of syphilis testing and treatment of pregnant women as well as other additional requirements have not reached yet.

On the way to the CS elimination Ukraine is facing a few challenges. There is an urgent need on further year the new strategy on STI/CS prevention with targets and targets indicators. In addition national protocols of the treatment of pregnant women should be adapted according to the European Guidelines as well as comprehensive data is required for surveillance and monitoring of CS elimination.
\end{abstract}

Keywords: congenital syphilis, HIV, mother-to-child transmission, elimination.

\section{Introduction}

For over a decade, WHO has adopted a numbers of policy documents on the global elimination of CS and new cases of HIV infection in infants and young children [1].

In 2007 WHO launched an initiative for the global elimination of congenital syphilis, outlined in "The global elimination of congenital syphilis: rationale and strategy for action" [2].

The global community has committed itself to eliminating mother-to-child transmission (MTCT) of HIV and syphilis as a public health priority [3].

Elimination of MTCT of HIV and syphilis is motivated by the fact that such a double elimination will facilitate the improvement of a wide range of results on the protection of the health of mothers and children. This integrated approach is necessary to improve the efficiency and quality of mother and child health $(\mathrm{MCH})$ services and to offer women more comprehensive primary care services. 